\title{
Editorial Conclusion: Kindness in the Review Process
}

\author{
Caroline Yoon \\ c.yoon@auckland.ac.nz \\ University of Auckland, Aotearoa New Zealand \\ Sean Sturm \\ s.sturm@auckland.ac.nz \\ University of Auckland, Aotearoa New Zealand \\ Molly Mullen \\ m.mullen@auckland.ac.nz \\ University of Auckland, Aotearoa New Zealand \\ Billie Lythberg \\ b.lythberg@auckland.ac.nz \\ University of Auckland, Aotearoa New Zealand \\ Alys Longley \\ a.longley@auckland.ac.nz \\ University of Auckland, Aotearoa New Zealand \\ Niki Harré \\ n.harre@auckland.ac.nz \\ University of Auckland, Aotearoa New Zealand
}

\begin{abstract}
A guiding ethos of the Agencies of Kindness project was that our academic practice should enact the very thing we researched. Our challenge as an editorial team was to bring kindness to the process of academic refereeing. The standard blind peer review process is often a disheartening experience, marked by shame, cruelty and disempowerment. We wondered if we could develop an alternative peer review practice, one that authors could look forward to, anticipate with pleasure, knowing that all participants were entering the process with an orientation of care. Could we enact a reviewing process that was motivating and joyous, while also being academically rigorous? One that supported scholars and built connections, strengthening a research community around the Special Issue thematics? One that placed respect and kindness at its core? Our efforts concentrated on offering two workshops, to which we invited all potential contributors to the special issue. In the first workshop, participants imagined together openings for kindness in the academic peer review: what would a kind review look like, what would it feel like? In the second workshop, participants implemented some of these ideas while reviewing submissions to the special issue.
\end{abstract}

Keywords: kindness; affect; peer review; kind review; feedback; editing

How to cite: Yoon, C., Sturm, S., Mullen, M., Lythberg, B., Longley, A., and Harré, N. (2021).

"Editorial Conclusion: Kindness in the Review Process," Knowledge Cultures 9(3): 206-219.

doi: $10.22381 / \mathrm{kc} 93202112$. 


\section{Introduction}

A guiding ethos of the Agencies of Kindness project was that our academic practice should enact the very thing we researched. As an editorial team, ${ }^{1}$ our challenge was to bring kindness to the process of academic refereeing. The standard blind peer review process is often a disheartening experience, marked by shame, cruelty and disempowerment. We wondered if we could develop an alternative peer review practice, one that authors could look forward to, anticipate with pleasure, knowing that all participants were entering the process with an orientation of care. Could we enact a reviewing process that was motivating and joyous, while also being academically rigorous? One that supported scholars and built connections, strengthening a research community around the Special Issue thematics? One that placed respect and kindness at its core?

Our efforts concentrated on offering two workshops, to which we invited all potential contributors to the special issue. In the first workshop, participants imagined together openings for kindness in the academic peer review: what would a kind review look like, what would it feel like? In the second workshop, participants implemented some of these ideas while reviewing submissions to the special issue.

\section{Workshop 1: Imagining the Kind Review}

The intention of this workshop was to collectively decide the 'rules' for the reviewing process for the Special Issue. We led a series of activities that were designed to facilitate our collective imagining and decision-making processes.

Niki Harré opened the workshop by inviting us to reflect on the best and worst reviews we had received as authors. She had asked us in advance of the workshop to send her examples of both: ones that fired our motivation for our work and those 'ghastly, painful reviews which made you feel both humiliated and furious.' We felt vulnerable sharing these reviews, but Niki encouraged us by sending copies of hers first, with both her best and worst reviews being rejections of her work. Together, we discussed what made some reviews belittling and demotivating, and others insightful and inspiring. This discussion generated twelve recommendations for conducting a kind review, which became a framework for our work in this special issue (see figure 1). 
Figure 1 Twelve recommendations for conducting a kind review

1. Affirm the person and the work in plausible, specific terms.

2. Do not assume you know the author's intention, motivation or how much effort the work has involved.

3. Try to find, and then describe, the strengths of the work.

4. Recognise that you do not speak for 'authority' or 'quality' in an abstract sense. Your perspective is particular to your training and reading of the piece. Acknowledge your perspective.

5. On the other hand, you are responsible to the community of readers. If you do not see how this work at this time will enrich this community of readers, you may need to say this.

6. See yourself as stretching the work, rather than finding fault with it.

7. Avoid condescending or rude language. This is not Parliament.

8. Consider the likely impact of your reviewer on the authors. If your review is likely to infuriate, distress or demotivate them, consider how you could convey your feedback in a more kindly manner. If you relish the idea of evoking these emotions, find a psychoanalyst.

9. Be specific. What criteria are you working on? In what ways does their work meet and/or not meet these criteria?

10. Try not to make claims about what the article does or does not do that are factually incorrect.

11. Don't be an asshole (see point 8).

12. If you can, offer concrete suggestions. It is not your job, however, to figure out how to make the piece 'work.'

Niki also led us in a questioning exercise, in which we posed questions about the review process, one after the other. We were restricted to asking questions, not answering or discussing them, which opened up space for imagining and wondering, rather than asserting or concluding. Some of our questions were:

- Should the identities of the reviewer and/or the author be hidden from each other?

- Is it ever appropriate for a reviewer to become a co-author of the piece? What would trigger this option, and how would it be initiated?

- Can reviewing take place via a meeting between the parties involved? How would such a meeting be structured?

- At what point is it acceptable, or even right, for a reviewer to walk away from a piece?

- What is the role of the editor? Should they 'censor' reviewers' comments at times, and if so, under what circumstances?

- Is the editor a mediator, a carer? Who must an editor care for?

- Is a review a 'critical conversation'? Importantly, when does it end, and who ends it?

This questioning exercise brought into focus the tensions involved in editing and reviewing, such as how processes developed to save time and streamline organisation and administration might also reduce agency. New tensions would arise if editors and reviewers were to assume responsibility for holding a review 
process that was kind. Niki was adamant that, in addition to practising kindness to those whose work was under review, we must also practise kindness to ourselves as editors and reviewers. Often editors and reviewers are an invisible resource, providing labour that is rarely analysed or acknowledged. This partly justified our large and collaborative group of editors, who could hold space for one another, the reviewers and the authors, and share the ensuing workload.

Next, Molly Mullen led a series of image theatre exercises to explore what the review process looks and feels like. The aim was to make some of what we had been sharing about review experience and process more visible and tangible; to see what might emerge when representing our thoughts and feelings about reviewing in embodied images, rather than written or spoken words. This activity involved working in two groups. Based on what had been shared in the session with Niki, each group was asked to use their bodies to make an image of what the typical academic review process looks like and then a second image of what a kind review would look like. The images could be literal or metaphorical. We viewed each image in turn. First, we named what it was we could see, what the bodies in the image were doing, in terms of posture, gesture, and facial expression, and how they were placed or arranged in space. In one image of the typical academic review process (see figure 2), three bodies sat in three chairs that were placed in a triangle, facing outwards so that none of the bodies could see each other. Arms were folded, faces were serious, staring into space (except during photographs!). In the centre of the triangle, behind each of the three chairs, a fourth body was curled on the floor with their back exposed and face in their hands. In one image of the kind review (see figure 3), two bodies were interlocked, their arms and backs forming steady supports for a third body that leaned back on them. This third body was oriented so that they looked upwards.

Figure 2 The typical academic review process

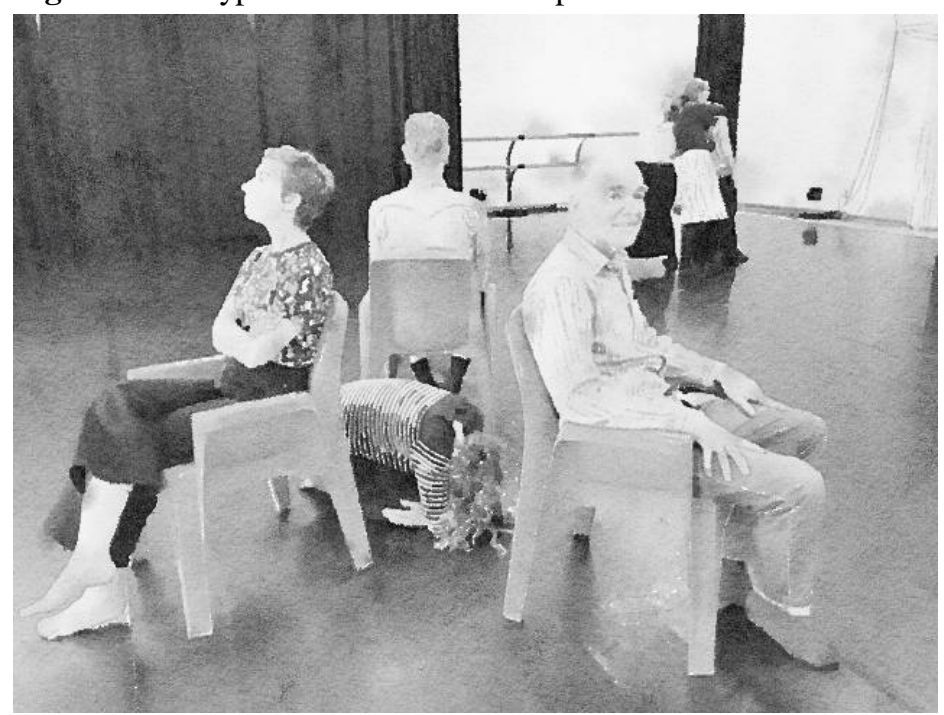


Figure 3 The kind academic review process

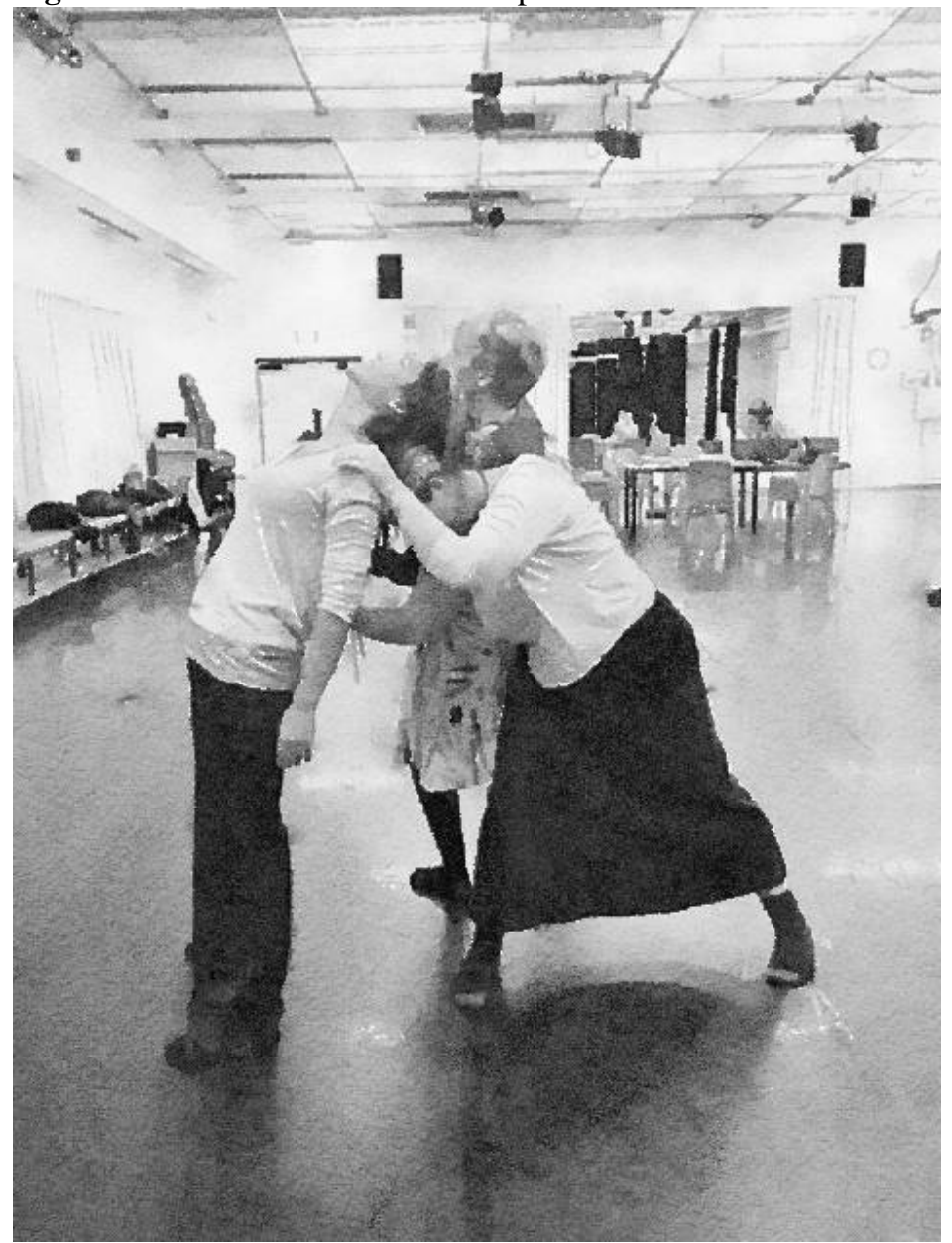

After naming what we could see, we interpreted the images, generating multiple possible meanings. We interpreted the three seated bodies in the first image (figure 2 ) as representing blind reviewers, and the body crouched and curled on the floor as the author of the work being reviewed. The positioning of the reviewers suggested their anonymity and indifference to the impact of their reviews on the author; the author's posture suggested their loneliness, shame, and isolation in the wounding of the review. The second image (figure 3) offered a completely different affective experience. We interpreted the two interlocking bodies as representing reviewers who were working together to support the author, represented by the third body that leaned on them. The author was able to look upwards, to see newness from their position. Finally, we reflected on what these images might tell us about what a kind review process would and would not look and feel like. We noticed that the first image was more physically stable than the 
second: the reviewers were settled in chairs in the first, while in the second, they kept having to adjust their movements to support the weight of the author. We acknowledged that a kind review process would likely involve more work, certainly from the reviewers, but also possibly the author, who would be encouraged to engage in additional labour to extend a manuscript that might have been rejected outright in a standard peer review.

Caroline Yoon then presented a series of diagrams showing different relationships between reviewers, authors, editors, and the work being reviewed (these are discussed in more detail in Yoon \& Penwarden, this issue). First, she showed diagrams (after Leemann, 2017) to describe relationships between a reviewer and an author's work that result in discouraging reviews. Three of these diagrams show the reviewer avoiding an encounter with the work by focusing instead on the work they wished was there, their own work, or the author (instead of the author's work) (see figure 4). The fourth diagram shows the reviewer attending to the work, but only to find fault and criticise, portrayed by the excessively large arrow (final diagram in figure 4).

Figure 4 Relationships between a reviewer and a work that can give rise to discouraging reviews

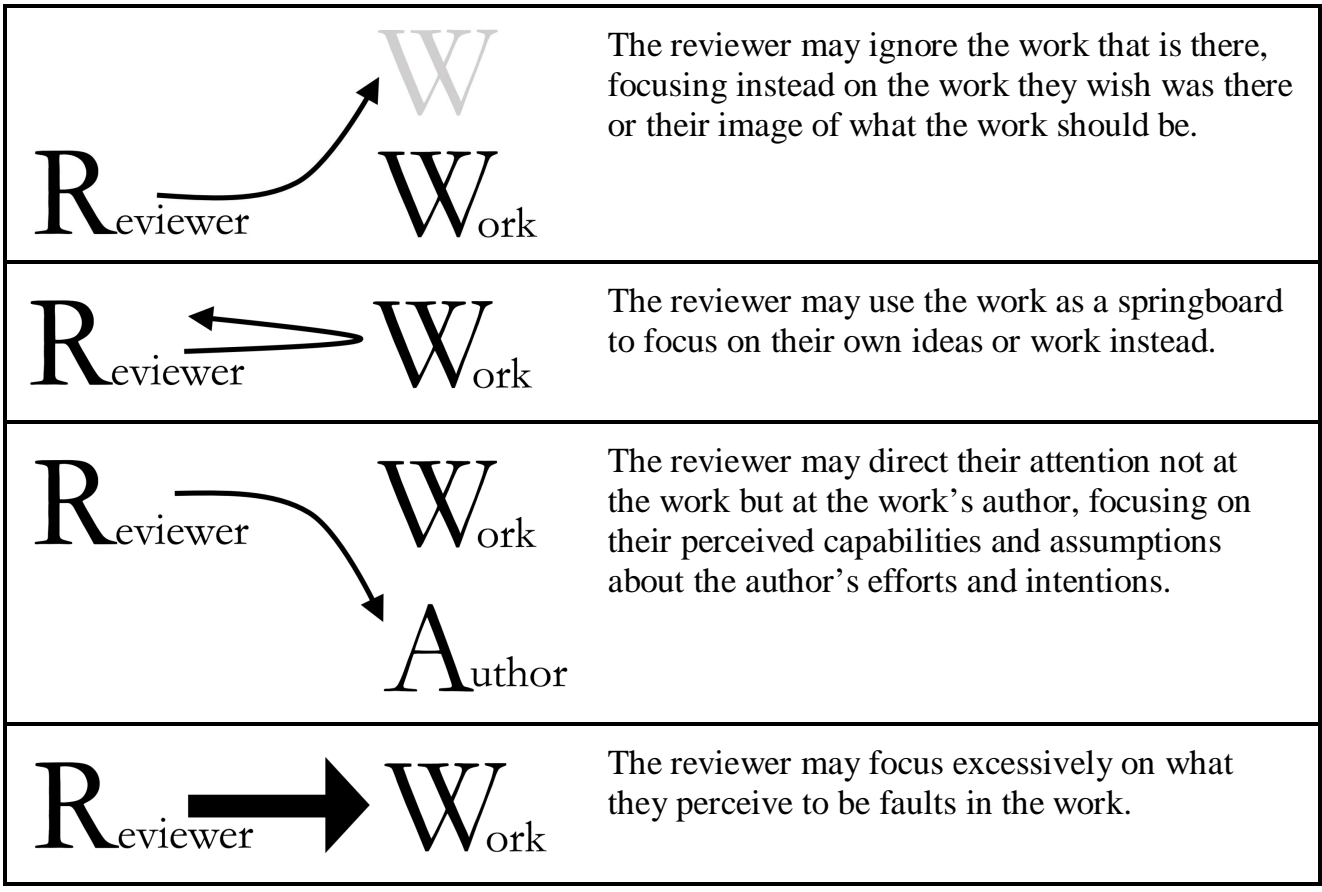

Next, she presented diagrams to describe different relationships that might support a reviewer to encounter a work with nonviolence (see figure 5). A key difference in these diagrams is the reverse direction of the arrow, which points from the work to the reviewer, rather than the other way around. This reversal demonstrates the 
reviewer's new focus on how the work affects them as they encounter it, rather than the other way around.

Figure 5 Relationships in a reviewer's nonviolent encounter with a work

The reviewer grounds themselves in an encounter
with the work by naming, without interpretation,
what is there. They focus on identifying
properties of the work that are available to them,
even if they think they are too obvious to
mention.

Finally, Caroline presented two diagrams to show relationships between the reviewers, editors and authors in academic refereeing. The first diagram (figure 6a) shows relationships in a standard peer-review process in which the editor collates and moderates independent reviews from reviewers and passes them on to the author. The second diagram (figure 6b) shows relationships in an alternative peer review process, inspired by a novel conversational format in Family Therapy called Reflecting Teams (Andersen, 1987). In the Reflecting Teams approach, the author is invited to listen to the reviewers discussing their reviews of the author's work in a conversation that is moderated by the editor. The reviewers are aware that the author can hear them, but they direct their conversation to each other, rather than addressing the author directly. This gives the author privacy and time to make sense of the reviewers' comments without being put on the spot and expected to respond immediately. The editor's role changes in this format. The editor is no longer expected to filter and coordinate the reviewer's independent comments into a single message for the author. Instead, the editor encourages the reviewers to share their thoughts with each other, inviting and generating a diversity of responses. We discussed how the combination of reviewers attending to a work with nonviolence and the authors being invited to listen to reviewers discussing 
their diverse reviews could support a more respectful reviewing process for all participants.

Figure 6 Relationships in a standard peer review vs in a reflecting team review

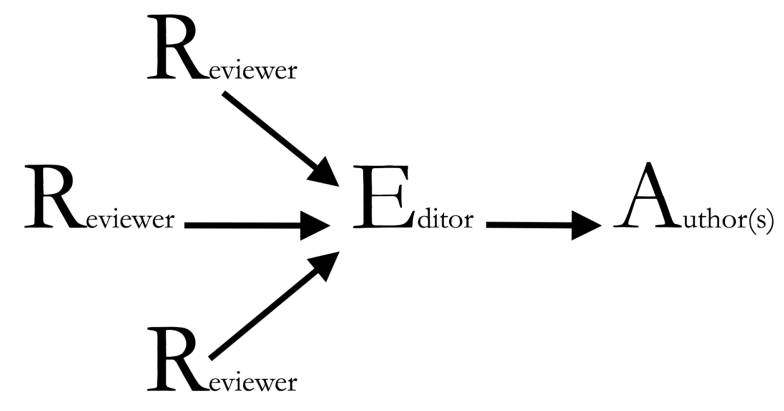

(a) Relationships in a standard peer review

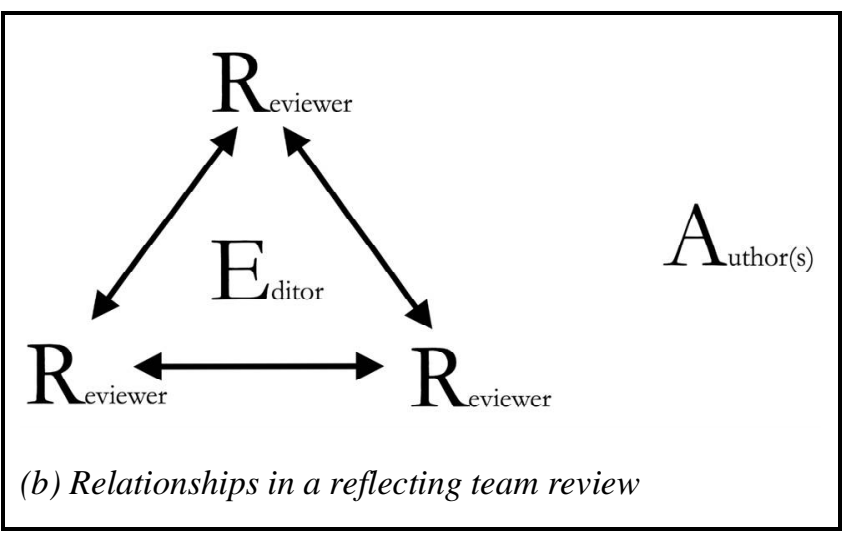

Towards the end of our workshop, Alys Longley led a discussion about time, temporality, relationality and medium. Questions arising from this session were numerous. What are some aspects of reviewing that can link to kindness, for example, how is time treated and accommodated in that process? How can we respect the time needs of writers and reviewers while also caring for the whole process? How do you treat relationality? How useful is the 'blindness' in blind peer review when it comes to kindness? Does blindness enable reviewers to detach from the kindness of personal interaction? How does medium matter? In terms of kindness, what is the difference between a conversational review, written feedback shared in person, and blind feedback? How does it matter if authors can respond to their reviewer, and the reviewer is held to account for the effects of their feedback?

At the end of the workshop, participants agreed that one way we could enact kindness was to give authors agency in the review process. We accepted that 
asking authors what felt kindest to them was not likely to generate a one-size-fitsall answer and that one of our responsibilities in holding a kind review would involve accommodating difference. In our call for submissions to the special issue, we invited authors to choose how they would like their pieces to be reviewed when they submitted their drafts. Authors could choose whether they would prefer blind or non-blind reviews and whether they would prefer to receive their reviews through conversation or writing, as individual author teams or in a more collective workshop format. Authors could choose to meet their reviewers more than once over time and were invited to offer suggestions for reviewers who could provide support in specific areas. As we were keen to support junior researchers and voices that might not otherwise be heard, we also offered an option for authors to work directly with a reviewer who joined them as co-author. We were committed to doing our best to meet these requests from authors in our exploration of how the review process might be pleasurable and supportive to all participants.

At the same time, we accepted that a review process that was more accommodating of different preferences would place additional responsibilities on the editorial team and would be more onerous to administer. Alys's discussion made us aware that time was a limiting factor and that, despite our attempts to accommodate differences and support authors in the process, there was a possibility that some submissions may not be ready for publication by our deadline. We anticipated dealing with this by encouraging authors of submissions that were not ready by the due date to continue developing their work for other publication opportunities, staying committed to their development as outside reviewers if possible.

\section{Workshop 2: Implementing the Kind Review}

We were pleasantly surprised that none of the authors of the more than ten submissions we received chose the standard blind review option. One author said they were happy with the standard blind peer review process but were also open to going with the flow. Other authors who indicated a review preference said they were interested in engaging with their reviewers within the review process. Thus, we decided to organise a second workshop in which authors could meet their reviewers and enter conversation with them as part of the review process. Following common practice in special issues, all potential authors were asked to serve as reviewers of other manuscripts submitted to the issue, with additional outside experts providing review on an as-needed basis.

Organising such a workshop was challenging. Although we had set a deadline for full drafts, the manuscripts we received were in various stages of development. Some manuscripts could have been published with very minor editing, whereas others were only partial drafts, with notes sketching out ideas still to be fleshed out. This created a tension for the organisers. We wanted our workshop to encourage and support authors with drafts that were still early in the writing process and to 
provide a space where they could explore interconnections between each other's works, and share and reflect on their writing practice. Yet this competed with the needs of authors with fully formed manuscripts, with one author questioning the value of attending such a workshop when their writing process was finished. We accepted that these authors needed critical feedback so they could move to the next stage of revising their drafts. We resolved this tension by explaining that the workshop review would serve different purposes for different authors: for authors of completed manuscripts, the workshop review might provide sufficient feedback for improving their drafts, and that these changes could be managed by the editorial team without requiring additional review. For authors of incomplete manuscripts, however, the workshop review would serve more to encourage and support the development of their ideas, and that additional reviews would be conducted once their manuscripts were completed.

Another tension arose between our desire for authors to be aware of each other's work, and restrictions on participants' time and energy for reviewing. While authors were willing to contribute to reviews, it was too much to ask all authors to read the 10+ submissions at the level of detail that would be expected of a reviewer. We settled on assigning each author two manuscripts to review and encouraged them to familiarise themselves with the rest of the manuscripts by reading the abstracts as a minimum. Each manuscript was also reviewed by at least one member of the editorial board, so each manuscript had a minimum of three reviewers. In addition, all contributors were invited to participate in the review sessions for each manuscript, with the number of participants in the review of each manuscript ranging from three to seven.

Conducting peer reviews in real time, through face-to-face conversations, introduced a tension that does not typically feature in written blind peer reviews. Receiving critical comments on one's work is a highly charged experience whether these comments are presented in writing or in spoken conversation. However, authors receiving written blind reviews can process these emotions in private, and the anonymous reviewers are not usually privy to them. In a face-to-face format, however, emotional responses are much more public. In our review conversations, we wanted reviewers to feel comfortable enough to share their thoughts on the manuscripts, even if they were critical. At the same time, we wanted authors to feel comfortable enough to ask reviewers for clarification or correct them where appropriate. How did we deal with this tension? First, most of the authors had participated in the first workshop on 'Imagining the Kind Review,' and were thus familiar with the ethos of the review conversations, and had contributed to our ' 12 principles for conducting a kind review,' which we circulated after the first workshop. Second, each review conversation began with a member of the editorial board asking the authors how they would like the session to be conducted and then following from that.

Reviewers and authors sat together around tables, with each review conversation taking 20 minutes. The authors of three manuscripts were unable to 
attend in person, in which case the reviewers recorded their conversations of them talking to the author(s). It was important to us that authors who had chosen to receive feedback in a personal and engaged way could actually listen to their reviewers' voices. It resulted in a very intimate reviewing process, compared with the standard blind review in which authors and reviewers are kept at a distance, neither entirely sure who the other might be. One author later reflected 'I came out of [the review workshop] feeling fantastic, grateful to [the organisers] for the time [they] put and thinking around time and pairing us with each other to have conversations, grateful for the care of the conversations and the sense of being held. Because what happens in a publication is you're in a community of practice with people that care about something that you also care about. And it was really empowering to have rich conversations around the thematics of kindness in this instance, and feel that we were working together to do this work, rather than my common experience of the blind review process, which is that I' $m$ being judged' (Personal Communication, 2021).

Another participant described the sense of comfort they experienced in the workshop as a reviewer. Reviewing in conversation with authors and other reviewers felt collegial. They noticed reciprocated smiles and body language, and could attend to how their feedback was received by authors in real time, often with enthusiasm and gratitude, but also by directly questioning the reviewer or asking for clarification. This reviewer felt able to ask more inquisitive and provocative questions than might be possible within a definitive, written review. The immediacy of the workshop setting also reduced the reviewer's fear that they may inadvertently misconstrue some facet of the author's work and provide a less-thanuseful review as a result. These social, collegial and affective aspects of the conversational review made the process feel more rewarding than the ofteninvisible labour of blind reviewing.

Our review workshop seemed to be appreciated by the attendees: we received positive comments from authors who had submitted complete drafts, as well as those whose drafts were incomplete. The author of an incomplete draft commented that the support of the review team and the questions they asked helped them to shape the final paper. We reflected that the face-to-face setting allowed reviewers to attend to work-in-progress in a generative way, rather than the standard desk dismissal due to its incomplete state. One author and reviewer commented that 'actually, that was the thing, it was really nice to read the unfinished work. And it was nice to feel that my work-in-progress was supported' (Personal Communication, 2021). There was agreement that this interim work-in-progress workshop could be adapted as a model for future special issues or edited volumes, and one author of a completed manuscript said they planned to use the model with their students. Authors found it motivating and empowering to share their work, it enabled connections to be made across articles in the edition, and it provided opportunities for the editors to bring back into the fold those authors whose articles risked veering away from the theme. 


\section{Reflections on the Kind Review}

Looking now across the contributions to this special issue, they exemplify very different definitions of and perspectives on kindness. To accommodate and nurture this diversity, it was critical for the editorial team to define what was meant by kindness in terms of the review and development process. In our attempt to bring kindness into the review process, we agreed that we wanted to deliver processes that would be generative and constructive for everybody involved. We also agreed that a kind, face-to-face review need be no less rigorous than a double-blind peer review, and that there is no kindness in withholding questions, advice or critique. Rather, through adherence to our ' 12 recommendations for conducting a kind review' and the reflections in the first workshop on how the review process really could be different, reviewers and editors found ways to offer critical comments in ways that were encouraging and inclusive as opposed to alienating and isolating. We acknowledge, however, that this assessment is based on our personal experiences of the process and on what participants felt comfortable to share with us. We cannot know what was not shared: while kindness enabled us to undo some of the power hierarchies of editing and reviewing, they were not completely flattened.

Our experiments with alternative review processes required us to rethink our role and accountability as editors. We formed a commitment to bringing everyone along to the satisfactory conclusion of the review process and, ideally, to publication. This meant rethinking the gatekeeping role of reviewing and editing. Editing can involve outsourcing critical judgment to others who don't have any stake in the work or publication; it can also involve desk rejecting an article without even offering it for review. Instead, as the first deadline for full submissions approached in preparation for the review workshop, we decided to encourage authors to submit unfinished manuscripts, rather than authors opting out of the process early because they hadn't completed their manuscripts. Engaging with work-in-progress is good writing pedagogy and something we regularly do with our students. A standard review process, however, emphasises product over process. It is rare for review processes to engage with the development of writing. There is a sense that this generates 'weak' as opposed to 'strong' academic practice. Herein lies the distinction between reviewer as gatekeeper and what we are calling the reviewer as ally. The responsibility of the gatekeeping reviewer is to control who enters the ivory tower; the responsibility of the ally is to support the movement of ideas. Such orientations can make a profound difference to the (affective) experience of a writer.

Editors have a role in enabling authors to become socialised into a discourse community, but it can be difficult for them to do that through the standard reviewing process because they are expected to remain at arm's length, precluding the opportunity to nurture the authors. The 'kind reviewing' process of this journal disrupted the norms of 'blindness' and 'distance' between author, reviewer and editor, and brought all of these actors together in direct relationship. In doing so, 
there was a sense that knowledge, ideas, inspirations and time were shared with generosity, rather than protected and measured. The collective aspect of the process motivated our work and brought a sense of being mutually supported, particularly at the most difficult moments of writing, reviewing and editing. In a very real sense, then, this volume emerges from a process of working, as Haraway (2016) suggests, 'with each other in all of our bumptious kinds [...] to make kin in lines of inventive connection' (p. 1).

\section{Acknowledgements}

We would like to acknowledge Victoria Wynne-Jones for her administrative and editorial assistance in assembling this special issue and in the research collaboration that informed it.

\section{Author contributions}

All authors listed have made a substantial, direct and intellectual contribution to the work, and approved it for publication. The authors take full responsibility for the accuracy and the integrity of the data analysis.

\section{Conflict of interest statement}

The authors declare that the research was conducted in the absence of any commercial or financial relationships that could be construed as a potential conflict of interest. Conflicts that the editors consider relevant to the content of the manuscript have been disclosed.

\section{Transparency statement}

The authors affirm that the manuscript represents an honest, accurate, and transparent account of the research being reported, that no relevant aspects of the study have been left out, and that any inconsistencies from the research as planned (and, if significant, registered) have been clarified.

\section{NOTE}

1. Note that we have chosen to present the authors' names in reverse alphabetical order, not by level of contribution, in the spirit of collective authorship embodied in its shared reflection.

Niki Harre, https://orcid.org/0000-0001-6378-324X

Alys Longley, https://orcid.org/0000-0002-7687-6290

Billie Lythberg, https://orcid.org/0000-0003-3310-6197

Molly Mullen, https://orcid.org/0000-0001-6567-3116

Sean Sturm, https://orcid.org/0000-0003-4011-7898

Caroline Yoon, https://orcid.org/0000-0002-3663-5441 


\section{REFERENCES}

Andersen, T. (1987). The reflecting team: Dialogue and meta-dialogue in clinical work. Family Process, 26(4), 415-428. https://doi.org/10.1111/j.1545-5300.1987.00415.x

Haraway, D. J. (2016). Staying with the trouble: Making kin in the Chthulucene. Duke University Press.

Leeman, J. (2017). Pragmatics of studio critique. In P. Fraser \& R. Rothman (Eds.), Beyond critique: Contemporary art in theory, practice, and instruction (pp. 181-194). Bloomsbury Academic. 